International Journal of Automotive and Mechanical Engineering (IJAME)

ISSN: 2229-8649 (Print); ISSN: 2180-1606 (Online);

Volume 13, Issue 3 pp. 3696 - 3709, December 2016

CUniversiti Malaysia Pahang Publishing

DOI: https://doi.org/10.15282/ijame.13.3.2016.13.0303

\title{
Pressure sores of human tissue damage during pelvic binder compression
}

\author{
I. Munandar ${ }^{1 *}$, S. Huzni' ${ }^{2}$, M.S. Ismail ${ }^{3}$ M.S. Shaari ${ }^{1}$ and A.K. Ariffin ${ }^{1}$ \\ ${ }^{1}$ Department of Mechanical \& Materials Engineering \\ Universiti Kebangsaan Malaysia, 43600 UKM Bangi, Selangor, Malaysia \\ *Email: ilfan.munandar@gmail.com \\ Phone: +6094246239; Fax: +609424622 \\ ${ }^{2}$ Department of Mechanical Engineering, Syiah Kuala University \\ Jl. Tgk. Syech Abdurrauf No. 7 Darussalam - Banda Aceh 23111, Indonesia \\ ${ }^{3}$ Department of Emergency Medicine \\ Universiti Kebangsaan Malaysia Medical Centre, 56000 Cheras, Malaysia
}

\begin{abstract}
Pelvic circumferential compression is a device used to reduce injury which inadvertently, cause soft tissue damage. When force is applied excessively to the pelvic binder, tissue is damaged due to prolonged high pressure. Therefore, effect from this interaction between tissue and pelvic binder is an important factor to avoid pressure sores due to human tissue damage. The aim of this study is to investigate the effects of human tissue interaction due to compression of the pelvic binder using a finite element modelling approach. A three-dimensional human pelvic model was developed to simulate pressure distribution on tissue interfaces. The applied loads with two different conditions - dry and wet skin were applied on both tips of the pelvic strap during binder-tissue interaction. The compression load of the pelvic binder was estimated on a pelvic strap in order to reduce pelvic fracture. The compression load was varied substantially between locations as well as between skin conditions. There were two straps on the pelvis. For pelvic strap 1, the pressure on the sacrum and ilium was higher than the pressure measured on pelvic strap 2 while pressure on the anterior area was the same for both pelvic straps. Analysis results showed that the pressure which developed between both tissue and pelvic binder exceeded the recommended pressure i.e. $\geq 9.3$ $\mathrm{kPa}$ at tissue interfaces. When pressure on tissue interfaces is not controlled, this condition can lead to tissue damage due to prolonged periods of time. Hence, to avoid tissue damage to the pelvic binder a cushion must be introduced to reduce the effect of tissue reaction from the prehospital device. Subsequently, tissue and pelvic binder interaction simulation results were compared with experimental data for validation in the model developed.
\end{abstract}

Keywords: Nonlinear material model; human tissue; FEM, pelvic binder; tissue interaction; pressure sores; tissue damage.

\section{INTRODUCTION}

Pelvic circumferential compression devices (PCCDs) have been developed to maintain the stability of pelvic bones and reduce the volume of pelvic fractures during injuries [14]. A number of PCCDs are used for patients who sustained pelvic fractures. To avoid tissue damage, the pressure recommended on tissue interfaces is kept below $9.3 \mathrm{kPa}$ for more than 2-3 hours, continuously [5]. In the experiment, testing pressure 
measurements on the interaction between tissue and pelvic binder were performed by researchers to determine the influence of PCCDs on patients [3, 4, 6-8]. All of these studies showed that the pressure on tissue interfaces exceeded the recommended pressure i.e. $\geq 9.3 \mathrm{kPa}$. The PCCDs is used to reduce injury in patients but at the same time can cause soft tissue damage due to excessive pressure on tissue interfaces $[4,6]$. It is difficult to quantify the physical effects of pressure in the region of the human pelvis in the experimental method. The reason is simply because it could pose a risk to the patient. Alternatively, cadavers could be acquired; however, they are very expensive. Therefore, the deformation and subcutaneous stress of tissue between tissue interactions could not be observed [9]. Thus, the finite element (FE) modelling should be conducted to find the behaviour and the effect of tissue mechanical response against PCCDs. FE simulation of tissue interactions was carried out by researchers to study the effect of contact pressure on tissue interfaces [9-16]. Based on these studies it showed that there were many factors influencing pressure on tissue interactions, such as geometry, material model, boundary conditions and applied load. However, the effect of human tissue interactions during pelvic binder compression using a FE modelling approach has not been studied before. Therefore, the FE modelling of the pelvic binder and tissue interactions would take into account these factors to properly simulate the phenomena of tissue interactions. One important factor in reducing the high pressure on tissue interfaces is friction coefficient, where the difference in friction coefficient gives a significant effect on the pressure obtained [13, 16-18]. This condition is parallel with studies by previous researchers who stated that risk of pressure sores on patients could be reduced by considering the condition of friction and shear stress on tissue interfaces [19].

The aim of this study is to investigate the effects of human tissue interactions from compression of pelvic binder using a FE modelling approach. Human tissue is considered to be anisotropic, nonlinear and an incompressible material model. The friction coefficients between the contact interface of tissue and pelvic binder were estimated in two different conditions i.e. dry skin and wet skin. The effects of the interactions between tissue and pelvic binder for different friction coefficients are discussed in this study. The analysis results showed that the FE modelling of human tissue interactions was appropriate to study effects of tissue interactions. FE modelling of tissue interactions was confirmed by experimental results on PCCDs.

\section{METHODS AD MATERIALS}

\section{FE Model of Tissue-PCCDs Contact Interface}

FE model of Tissue-PCCDs Contact Interface was developed to study the effects of interactions between tissue and prehospital device. The model consists of the human pelvis, pelvic structure, PCCDs and spine board which were modelled separately based 


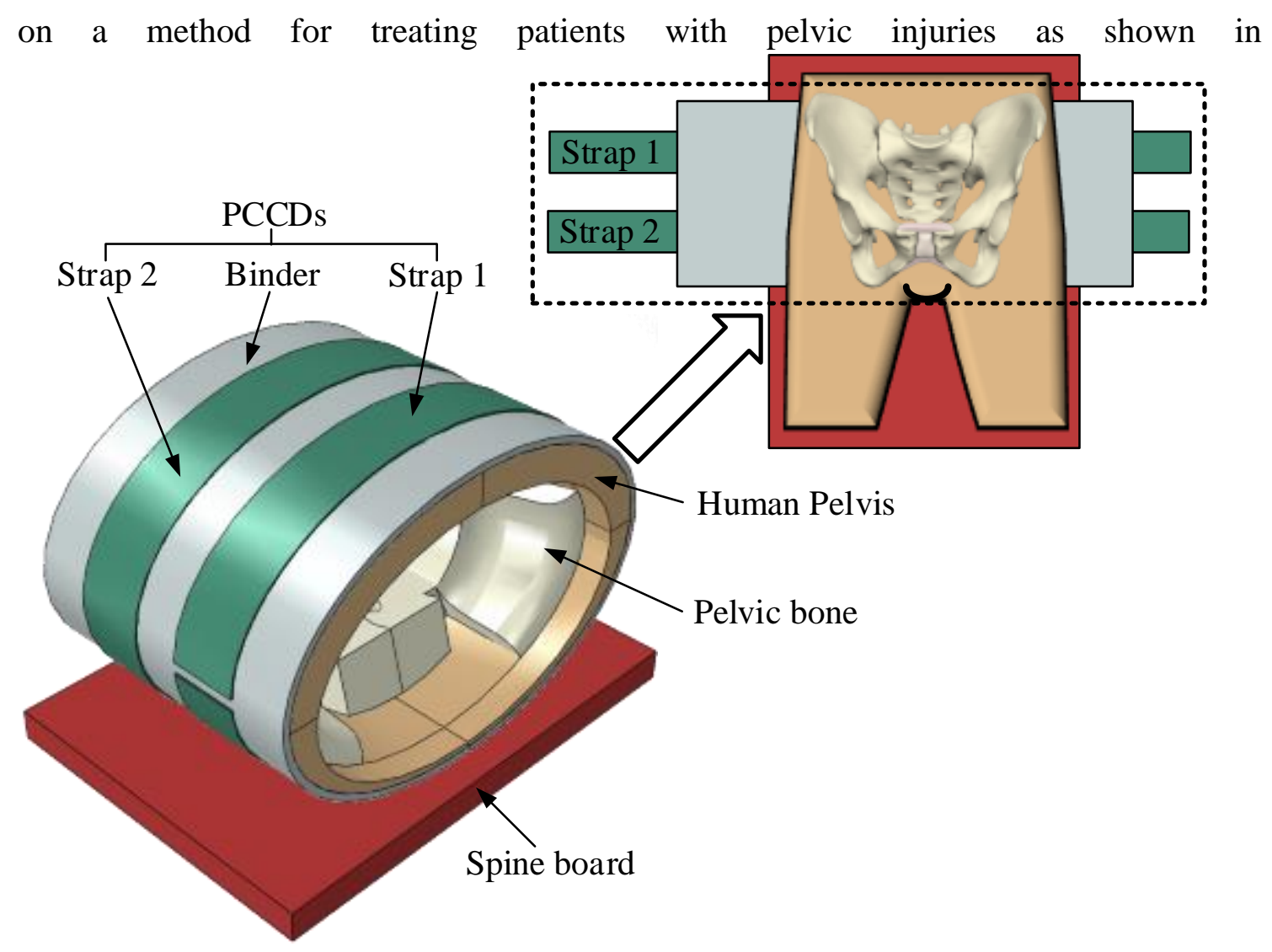

Figure 1. The FE model development of the tissue-PCCDs was modelled only on the pelvic area, which sustained interactions between tissue and prehospital device. The three-dimensional (3D) geometry of the human pelvis was simplified based on the model of CIRS Dynamic Pelvis Phantom as shown in Figure 2. The dimensions of the human pelvis are $200 \mathrm{~mm} \times 300 \mathrm{~mm} \times 200 \mathrm{~mm}$ (following a standard model of the CIRS Dynamic Pelvis Phantom). 


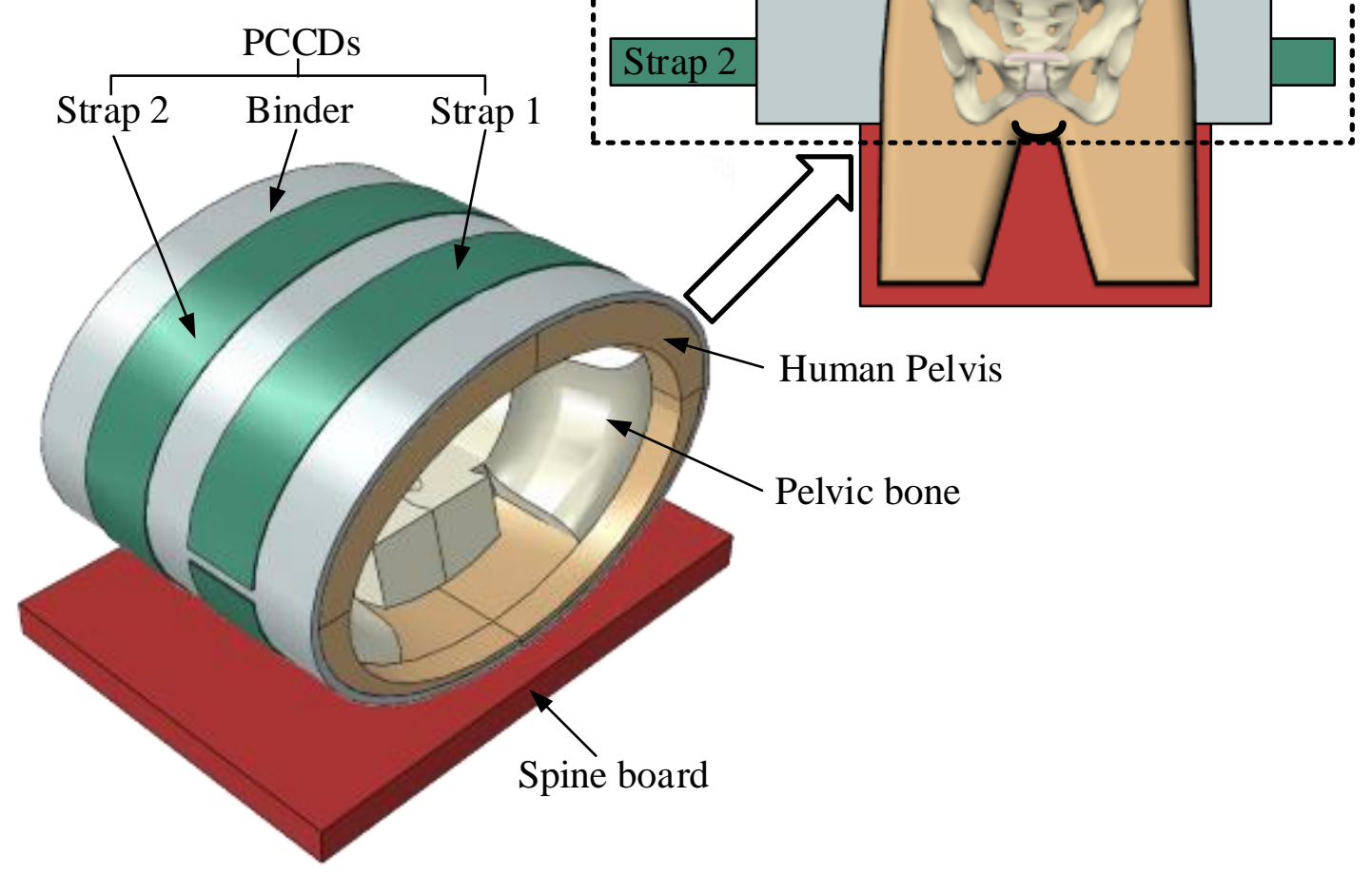

Figure 1. FE model of tissue-PCCDs contact interface.

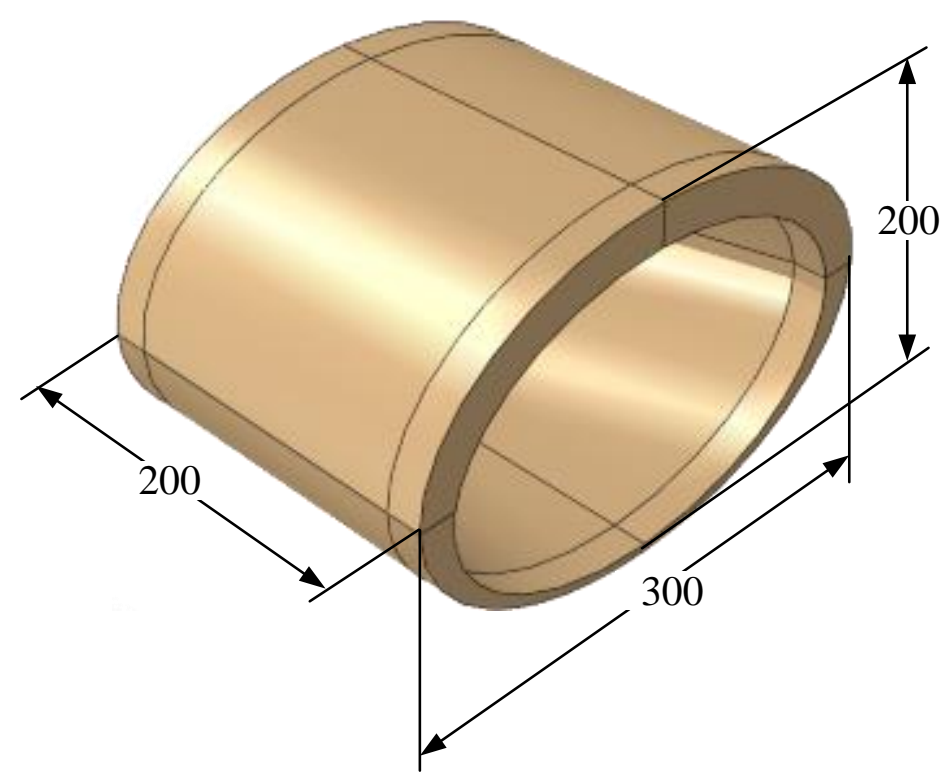

Figure 2. Geometry of the human pelvis.

Figure 3 shows the development of a simplified model for pelvic bones based on clinical measurement data on the pelvic bone structure by [20] and the shape of the pelvic inlet, pelvic outlet, pelvic cavity and pubic arch by Snell [21]. Figure 3a shows the measurements of the pelvic structures, which include the transverse diameter, oblique diameter I, oblique diameter II and the anatomical conjugate measuring 135- 
$140 \mathrm{~mm}, 120-125 \mathrm{~mm}, 115-120 \mathrm{~mm}$ and $\sim 120 \mathrm{~mm}$, respectively. While the interspinous distance and the intercristal distance are $260 \mathrm{~mm}$ and $290 \mathrm{~mm}$, respectively. The size of the pelvic inlet between male and female is similar, but the shape and size of the pelvic cavity of the female is larger and the pelvic outlet is wider than the male, as shown in Figure 3b. This is the main difference between the two types of pelvic structures because the female pelvis is appropriate for the process of childbirth [21]. The PCCDs model was developed based on data obtained from the prehospital device that was developed by Ismail, Johar [3]. All of these models were reprised in the FE model to study the effects of interactions that occur between human tissue and pelvic binder.

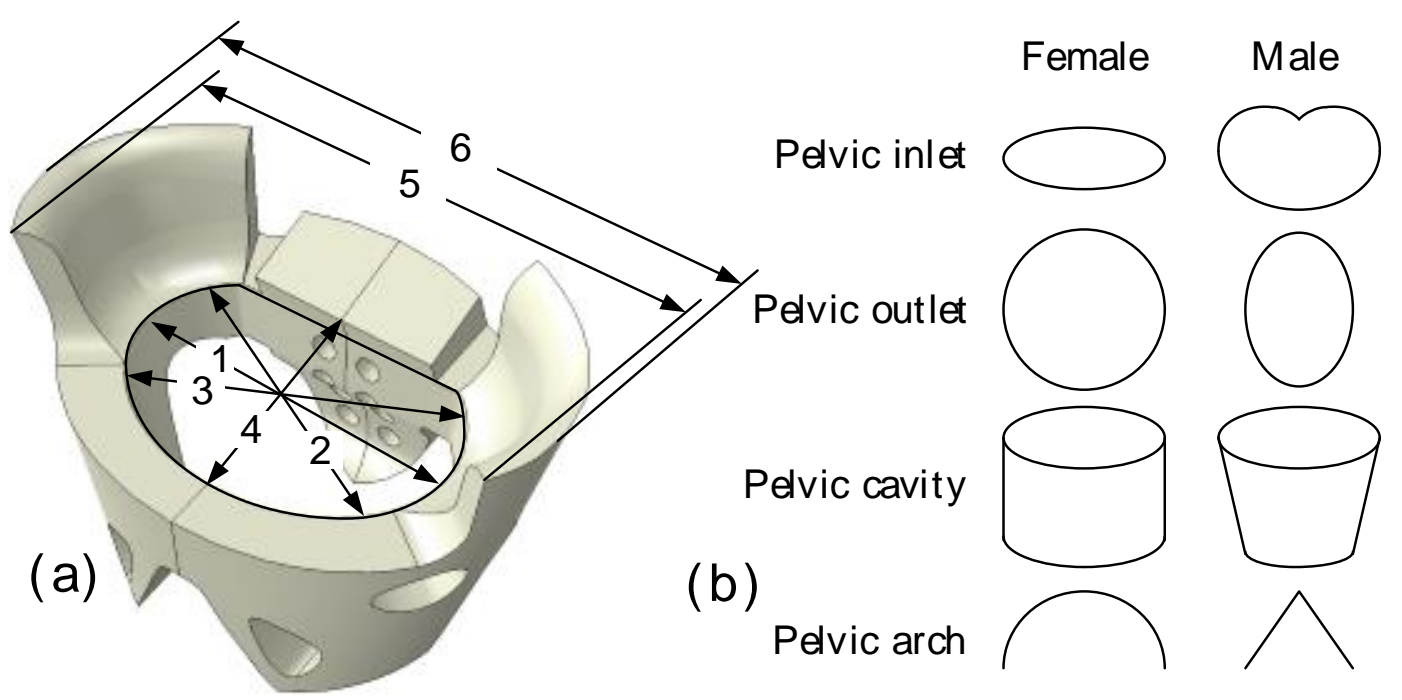

Figure 3. Structure of pelvic bone (a) pelvic measurement; (1) transverse diameter; (2) oblique diameter I; (3) oblique diameter II; (4) anatomical conjugate; (5) interspinous distance; (6) intercristal distance; (b) difference between the shape of the female and male pelvic bone. Source: Snell [21] for (b).

\section{Mechanical Properties}

In this study, the PCCDs were divided into two main parts. The first part was the main frame of the pelvic binder and the second part was a double tightening belt placed at the greater trochanter and the iliac. The main frame of the pelvic binder was made of polyurethane, while the belt was made of nylon [3]. The pelvic bone structure and spine board in the model were considered to be rigid. It was taken into account because the deformation of the pelvic bone structure and spine board were smaller than the deformation experienced in human tissue [11]. Mechanical properties of the pelvic bone and spine board were adopted from related literature in Table 1. The human tissue material model and mechanisms of tissue interactions modelling is briefly discussed below.

Table 1. Mechanical properties of the pelvic bone and spine board [13, 22].

\begin{tabular}{lccc}
\hline & $E(\mathrm{MPa})$ & $v$ & $\rho\left(\mathrm{kg} / \mathrm{m}^{3}\right)$ \\
\hline Pelvic Bone & $7 \times 10^{3}$ & 0.3 & \\
Spine Board & $14 \times 10^{3}$ & 0.4 & 437 \\
\hline
\end{tabular}

Human Tissue Material Model 
The soft tissue of the human pelvis model was modelled using anisotropic hyperelastic material model. The model is appropriate to describe the anisotropic material, large strain and large deformation with distributed fibre orientations. In this study, nonlinear material model of human tissue was represented by the Gasser-Ogden-Holzapfel material model. Annaidh, Bruyere [23] have successfully applied the Gasser-OgdenHolzapfel model to simulate the anisotropic behaviour of human tissue. In their study, the model was limited to simulating tensile tests in predicting the response of the mechanical behaviour of human tissue. The strain energy function $(\psi)$ of the GasserOgden-Holzapfel model can be explained in the following equation (1)

$$
\Psi=\frac{\mu}{2}\left(I_{1}-3\right)+\mu \frac{k_{1}}{k_{2}}\left\{e^{k_{2}\left[\kappa I_{1}+(1-3) I_{4}-1\right]^{2}}-1\right\}
$$

where $\mu$ is the shear modulus, $\mathrm{k}_{1}$ is the initial slope, $\mathrm{k}_{2}$ is a stiffening parameter, $I_{1}$ and $I_{4}$ are the anisotropic invariants. The parameter $k$ is the dispersion factor with $0 \leq k \leq 1 / 3$, in which the fibre orientations is aligned when $k=0$ and if $k=1 / 3$ then the material becomes isotropic as shown in Figure 4.

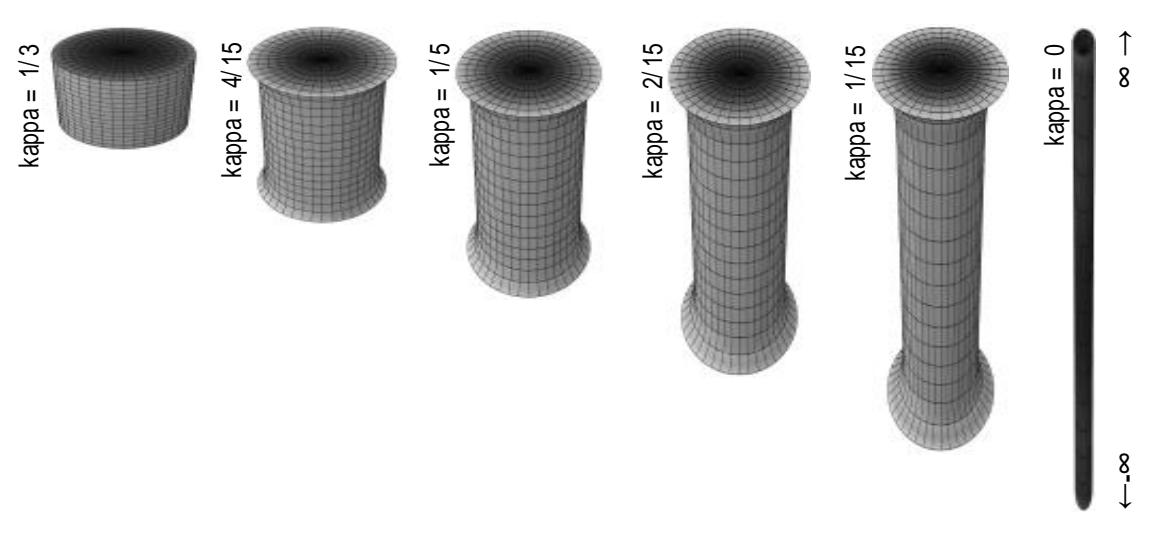

Figure 4. Three-dimensional representation of the orientation of collagen fibres.

The numerical value of the constitutive parameters $\mu, \mathrm{k}_{1}$ and $\mathrm{k}_{2}$ can be determined by the following Eq. (2)

$$
E_{1}=\frac{3+8 k_{1}(1-3 \kappa)^{2}\left(1-3 \cos ^{2} \gamma \sin ^{2} \gamma\right)}{1+2 k_{1}(1-3 \kappa)^{2} \sin ^{4} \gamma} \mu
$$

where, $k_{1}=\tan \Theta$ and $k_{2}=-1 / k_{1}$

where $\gamma$ is the orientation of longer lines and $\Theta$ is the preferred orientation. The material properties of human tissue obtained from experimental data of previous researchers with ABAQUS parameters used in this study were $C_{10}=\mu / 2, k_{1}^{\prime}=k_{1} C_{10}$ and $k_{2}^{\prime}=k_{2}$ [23].

Table 2 shows the material parameters that are used in this study to define general soft human tissue. 
Table 2. Material parameters for hyperelastic material to define soft human tissue.

\begin{tabular}{ccc}
\hline$C_{10}(\mathrm{MPa})$ & $k_{1}^{\prime}(\mathrm{MPa})$ & $k_{2}^{\prime}$ \\
\hline 0.1196 & 24.4715 & 0.0049 \\
\hline
\end{tabular}

\section{Human Tissue-PCCDs Interaction}

In FE modelling of the interactions between tissue and PCCDs, the body force of a human pelvis was defined as the applied load. Based on Bottlang et al. [24], the compression force is estimated on a pelvic binder in order to reduce unstable pelvic fracture i.e. 180 N. Displacement was applied on both tips of the pelvic straps during binder-tissue interactions to describe the compressive force of the pelvic binder used. Analysis of the interactions between tissue and PCCDs was conducted on FE software using a penalty contact method. The friction coefficients between the contact interfaces of tissue and pelvic binder were determined based on two different conditions i.e. 0.3 in dry skin and 0.8 in wet skin [19]. This factor was taken into account because there is a correlation between mechanical behaviour and damaged tissue, in which tissue damage can be avoided by reducing friction and shear force on tissue interactions [19].

\section{Material Model Validation of Human Tissue}

Validation of the material model used was conducted in FE simulation in two experiments. First, a uniaxial tensile test according to ASTM standard D412 [24]. Dimensions of the tensile test specimen can be seen in

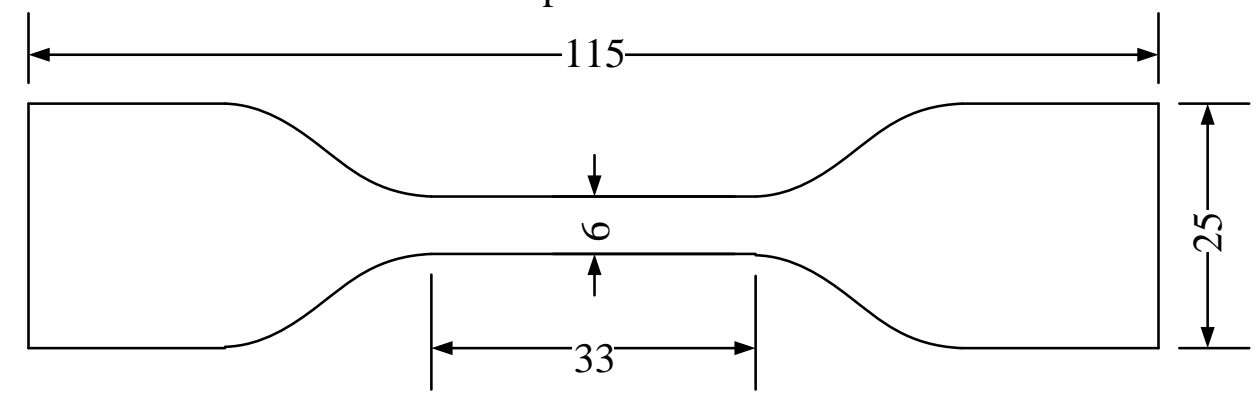

Figure 5 with a thickness of $2.25 \mathrm{~mm}$. In the second simulation, compression test was conducted according to the experimental apparatus of in vivo facial skin implemented by Flynn, Taberner [25] which was also compared to validate the material model used. The FE model of the in vivo facial skin experiments with a thickness of $1.15 \mathrm{~mm}$ is shown in Figure 6. In experimental studies of the compression test, FE modelling of skin was divided into two circular partitions: the first partition is the boundary ring and the second, is a partition of the contact area between skin and probe. The boundary ringpartition is a non-contact area whereas the outside area of the boundary ring-partition represents the contact area between skin and support plate. 


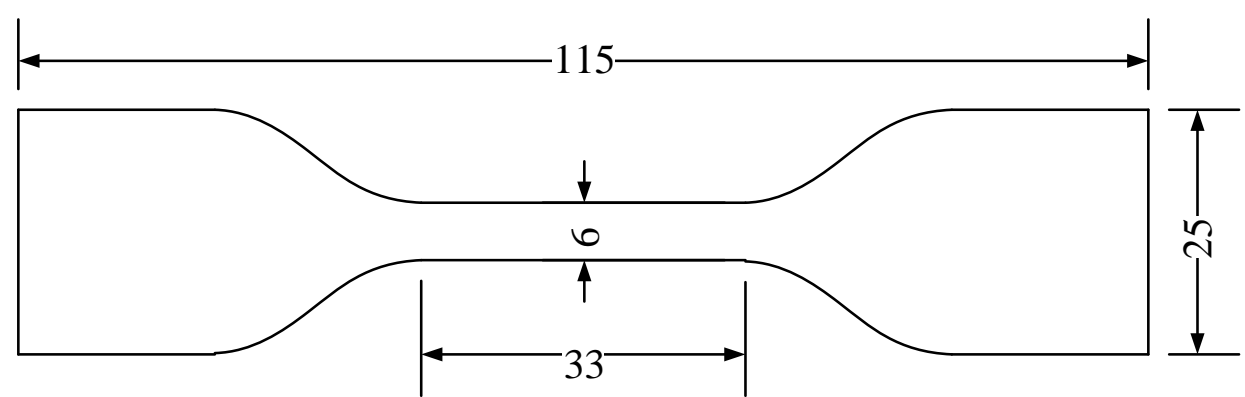

Figure 5. Dimensions of the tensile test specimen ( $\mathrm{mm})$.

The simulation results of the tensile test showed that stress is influenced by the parameter, $k$ in which stress is found to decrease with the increasing value of $k$. Figure 7 shows a comparison of stress-stretch with different values of parameter, $k$. It was found that the value of parameter $k$ appropriate for the material used was 4/15 compared with experimental data from Annaidh, Bruyère [24]. The analysis of per cent difference fit between the FE method and experimental method was $1.54 \%$ with $R^{2}=0.9798$. It showed that human tissue behaviour can be predicted by the nonlinear material model of Gasser-Ogden-Holzapfel. Validation of the material model of human tissue was also performed through the FE model for compression tests, as shown in

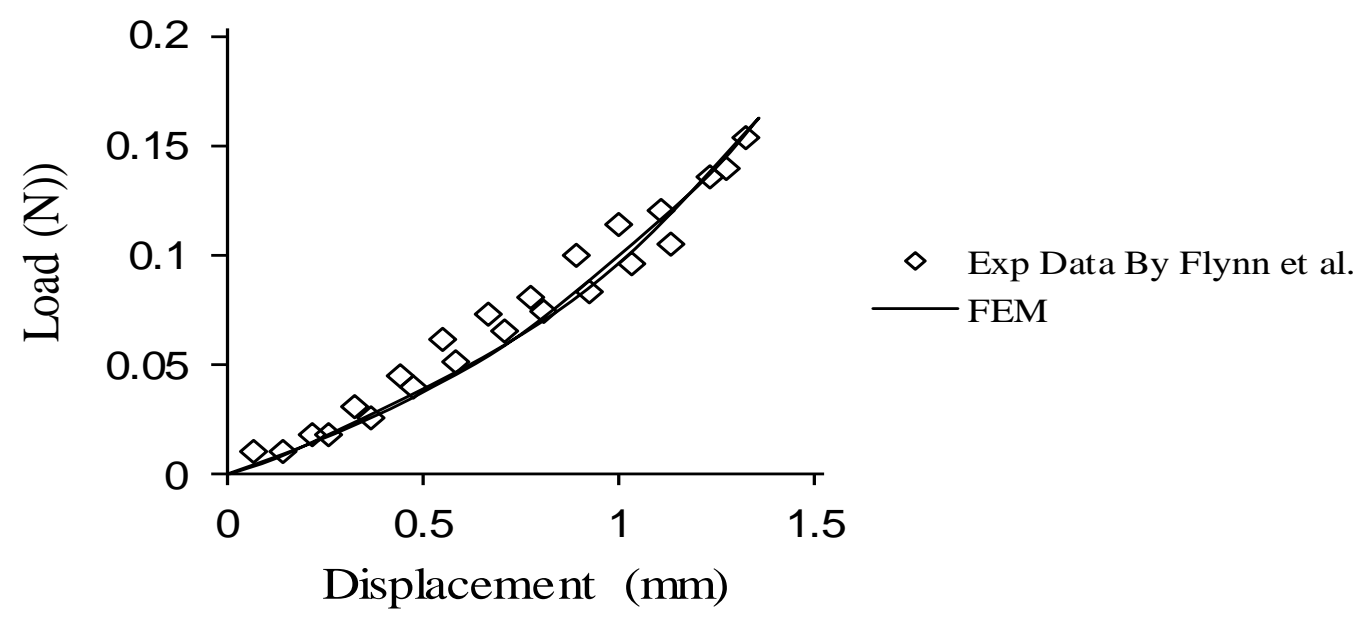

Figure 8. It was found that the per cent difference fit between the FE method and the experimental method was $1.44 \%$ with $R^{2}=0.9997$. Comparison of results for both the FE and experimental method showed that the model is able to predict human tissue behaviour in various tests. 


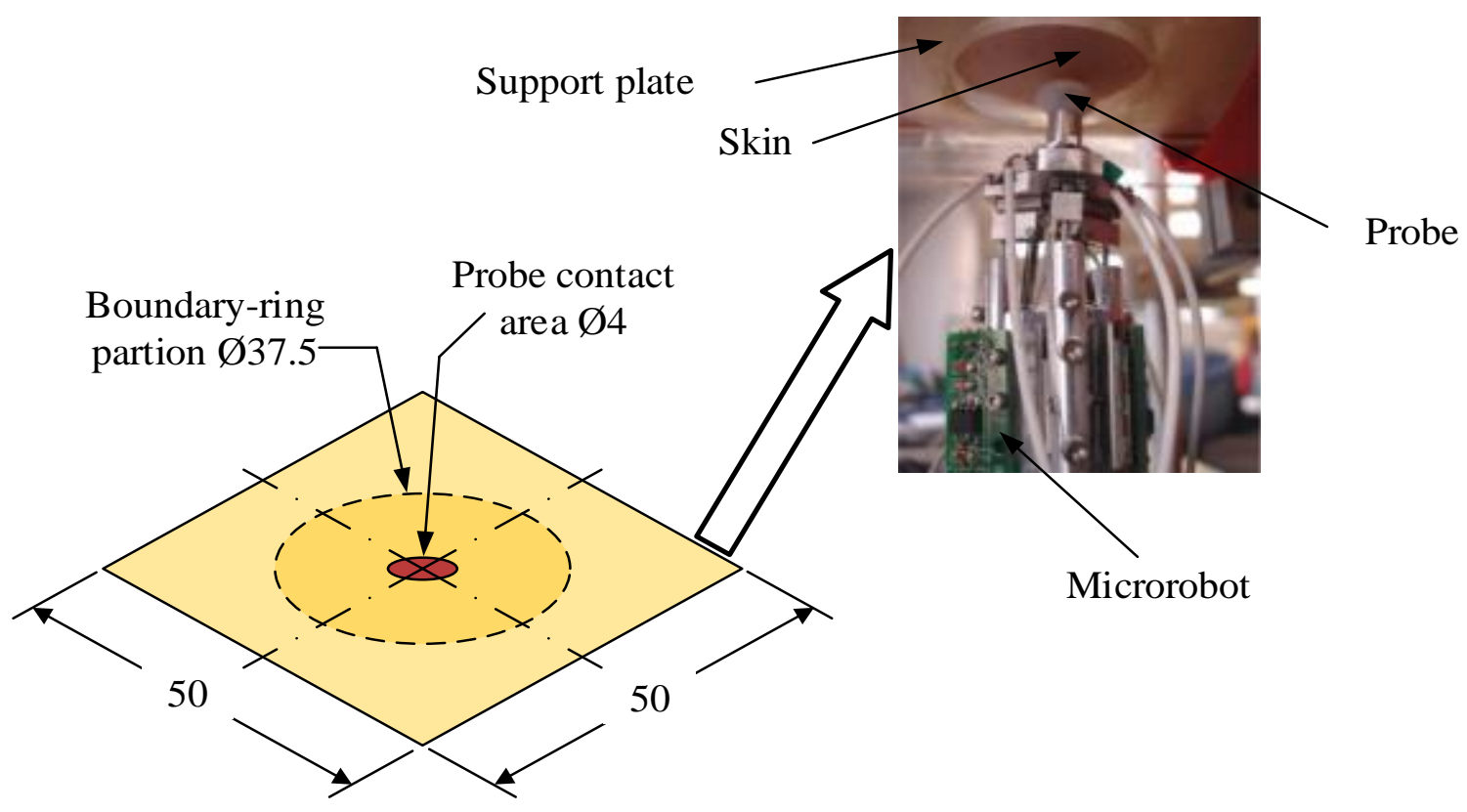

Figure 6. FE model of the in vivo facial skin experiment $(\mathrm{mm})[25,26]$.

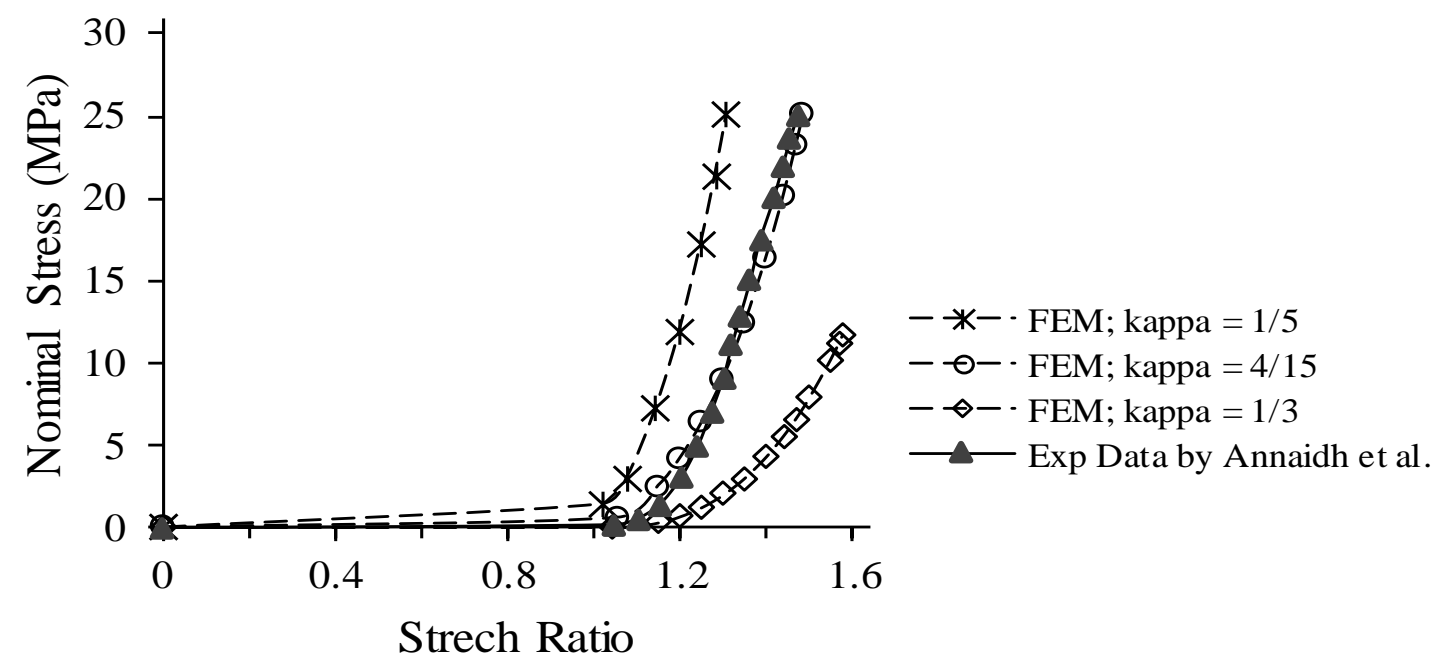

Figure 7. Comparison between FE model and experimental data from tensile test specimens. 


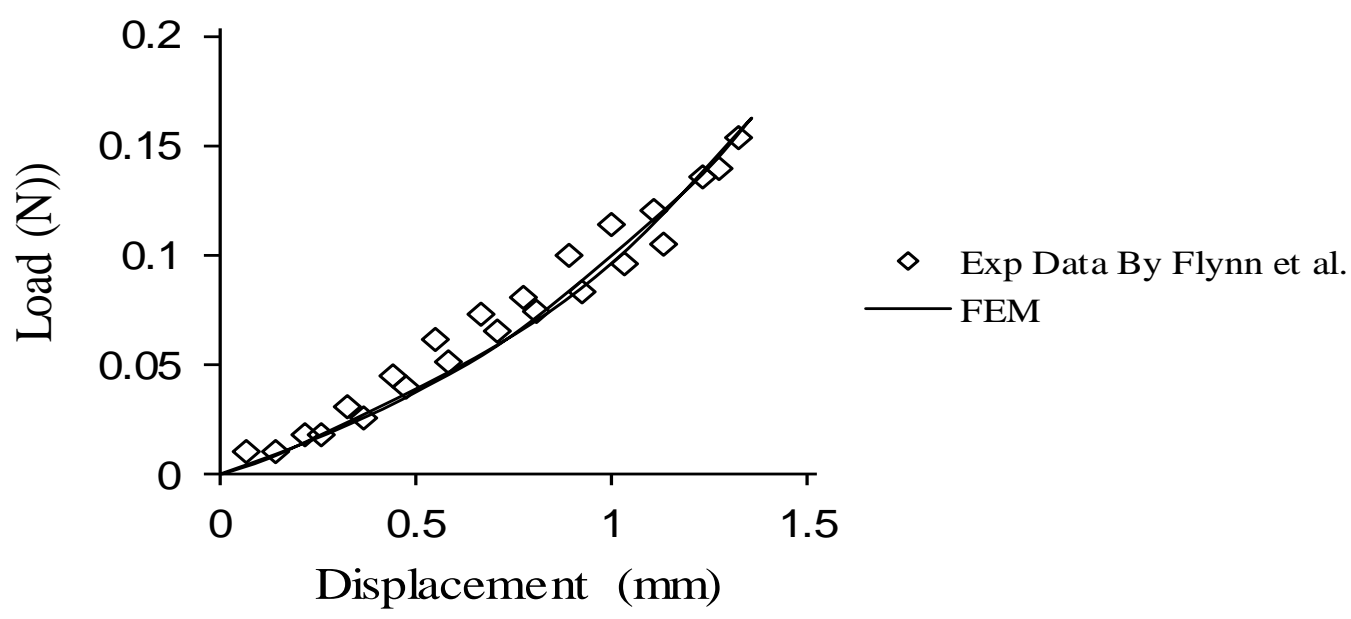

Figure 8. Comparison between FE model and experimental data from compression tests.

\section{RESULTS AND DISCUSSION}

Figure 9 shows the distribution of contact pressure between tissue and pelvic binder. It represents pressure on the posterior area which is higher than pressure in the anterior and iliac area. This condition is appropriate with the experimental data published by previous researcher [3], in which maximum contact pressure occurs on the posterior area. The pressure distribution on the left area of the iliac, right area of the iliac and the posterior area are shown in Figure $9 \mathrm{a}, \mathrm{b}$ and $\mathrm{d}$, respectively. It can be seen that the contact pressure on strap 1 is higher than the contact pressure on strap 2, while the contact pressure on the anterior area is the same on both the pelvic straps as shown in Figure 9c. The irregular pattern and contact distribution are caused by uneven compression during tightening of the PCCDs straps [8]. Even though the applied force for strap 1 and strap 2 are similar, the pressure exerted by the pelvic binder is significantly higher on strap 1. This is due to the different locations of straps that are placed on the structure of the pelvic bone.

A comparison for prediction of maximum contact pressure location between the FE model and volunteer experiments can be seen in Figure 10. In the FE model, prediction of maximum contact pressure is located under the pelvic bone structure of the sacrum section. Pressure sores mostly occurred between a bony prominence and an external support surface (such as pelvic binder or spine board) [12, 14]. During the tightening process, the soft tissue undergoes maximum deformation due to the external mechanical load from the straps. This finding is also consistent with the findings of a study based on experiments with volunteers conducted by Knops, Van Lieshout [8] and Grap, Munro [27]. However, finding the maximum value for contact pressure between the FE model and volunteer experiments by Knops, Van Lieshout [8] was different. This is because of differences in the design and characteristics of the PCCDs used [7]. A comparison between the FE model and volunteer experiments revealed a significant correlation as shown in Figure 10. The soft human tissue reaction was relative to compression from the pelvic binder. Therefore, this indicated that the maximum contact pressure location between tissue and pelvic binder could be properly simulated using FEM. 


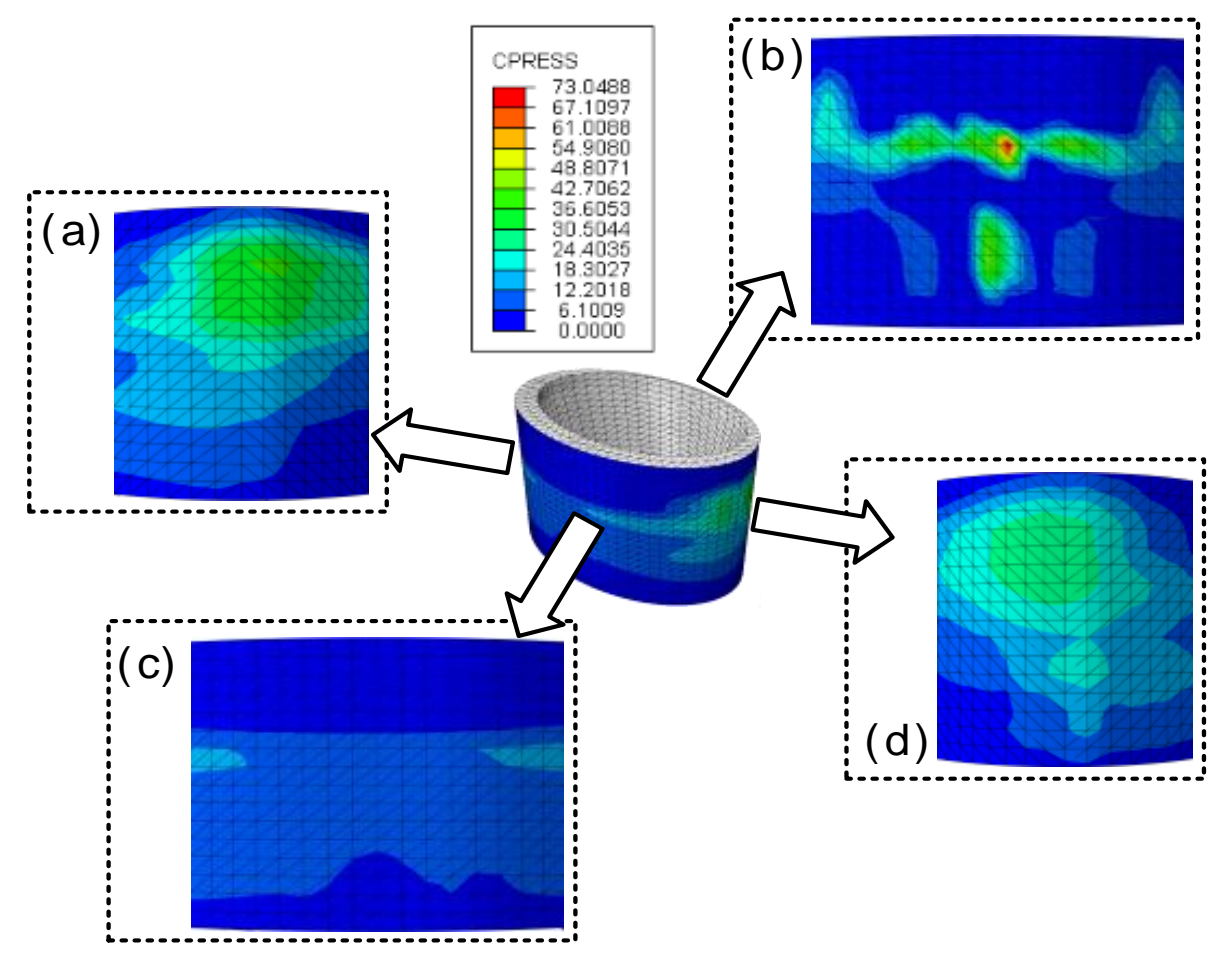

Figure 9. The contact pressure distribution $(\mathrm{kPa})$ (a) right area of iliac; (b) posterior area; (c) anterior area; (d) left area of iliac.
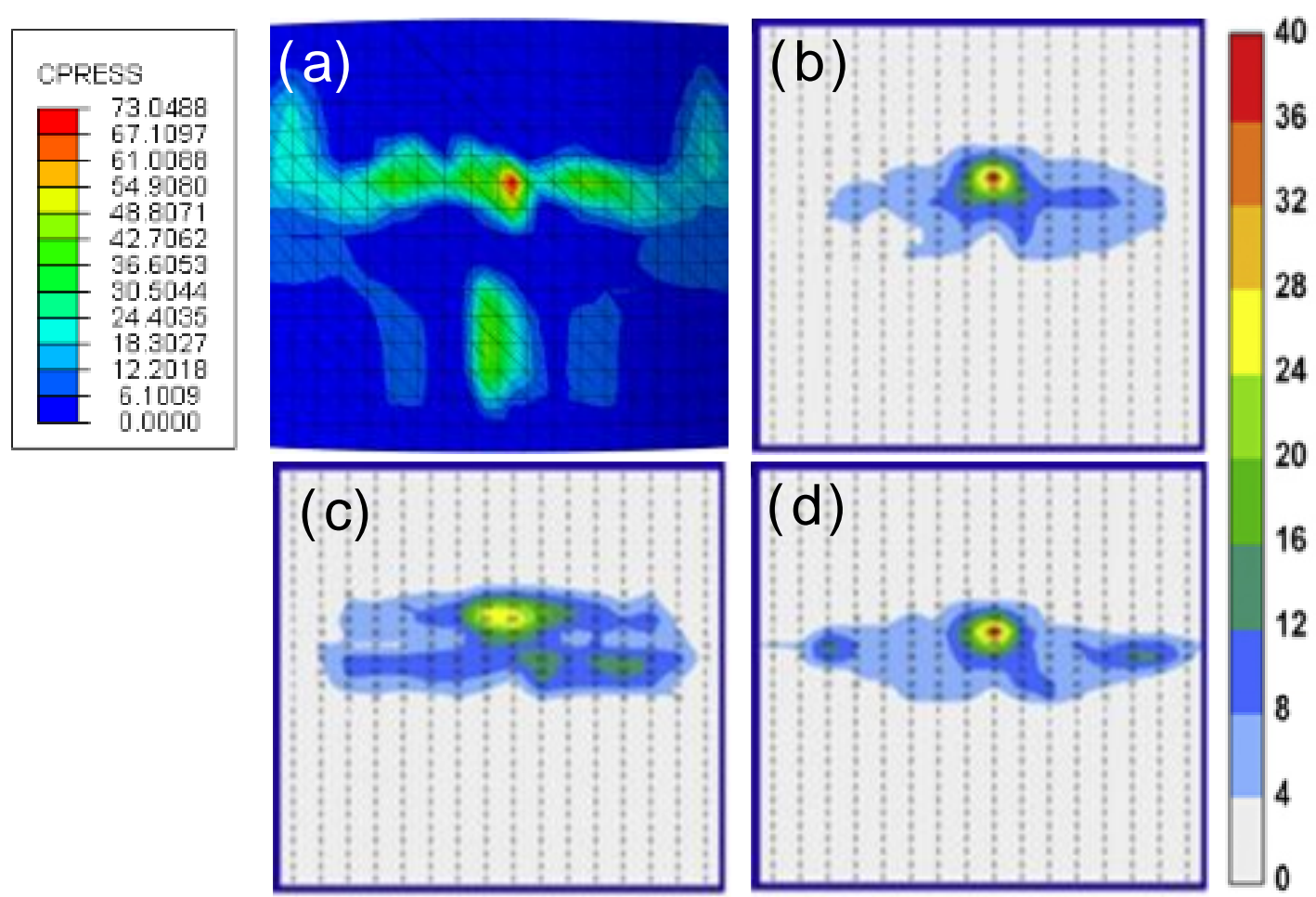

Figure 10. A comparison for prediction of maximum contact pressure location with volunteer experiments ( $\mathrm{kPa}$ ) (a) FE method (BRIM ${ }^{\mathrm{TM}}$ Immobilizer), in the present work; (b) volunteer experiments (SAM-Sling ${ }^{\mathrm{TM}}$ ); (c) volunteer experiments (Pelvic Binder $^{\mathrm{TM}}$ ); (d) volunteer experiments (T-POD $\left.{ }^{\mathrm{TM}}\right)$. Source: Knops et al. [8] for (a), (b) and $(\mathrm{c})$. 
The maximum contact pressure on the posterior and iliac area can be seen in
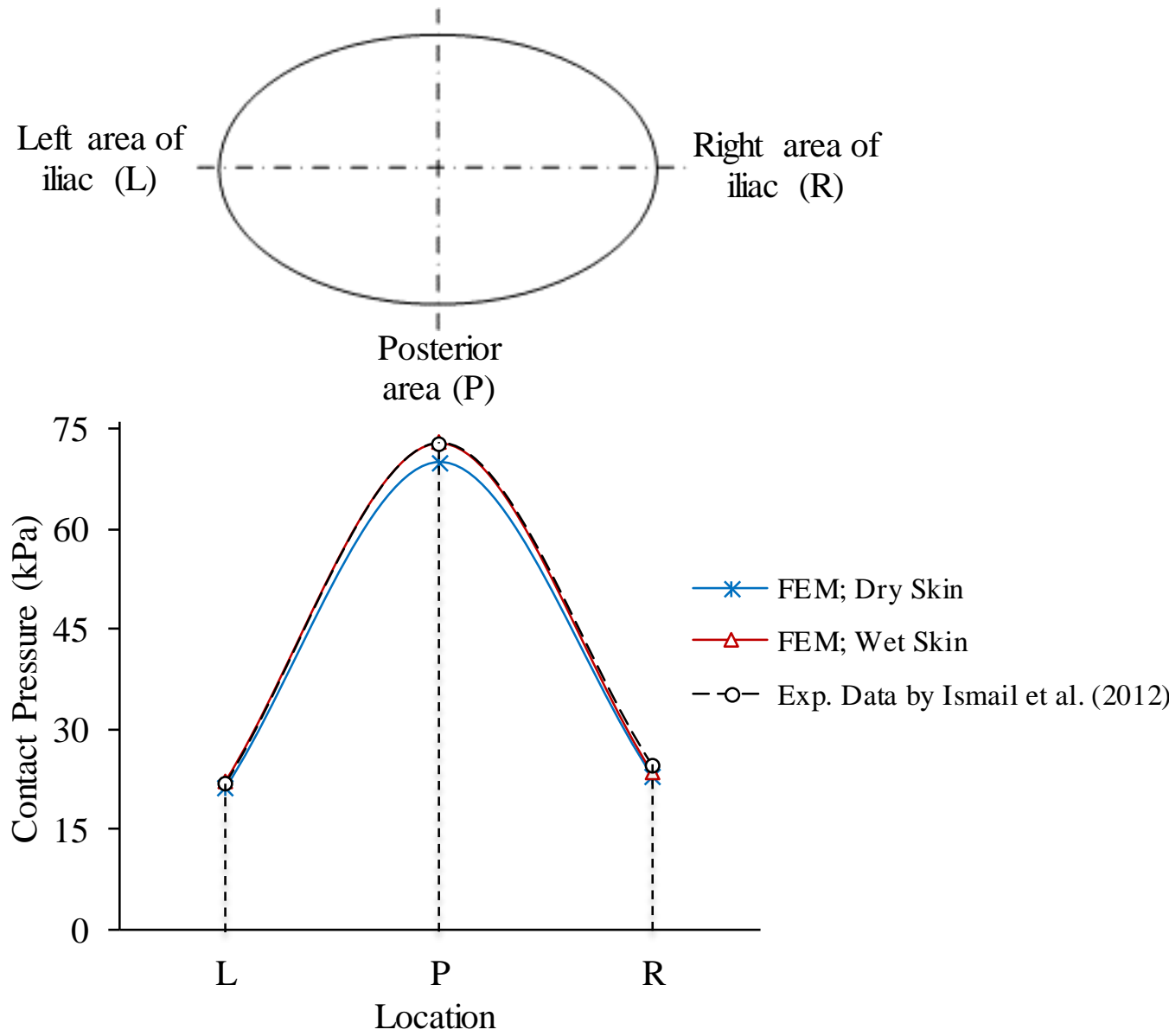

Figure 11. The figure shows that the contact pressure value on the posterior, the left and the right iliac area are quite near to the experimental results by Ismail, Johar [3]. For validation of the model developed, the contact pressure results obtained from the FE simulation was compared with findings of the experimental results by Ismail, Johar [3]. It was found that the average per cent difference between the FE method and dry skin condition and the experimental method was $4.53 \%$, while the average per cent difference between the FE method and wet skin condition and the experimental method was $2.13 \%$. This showed that the model of the tissue-PCCDs contact interface was able to predict the interaction behaviour between tissue and pelvic binder. These findings also indicate that the model is appropriate for further studies on the effects of human tissue interactions. 

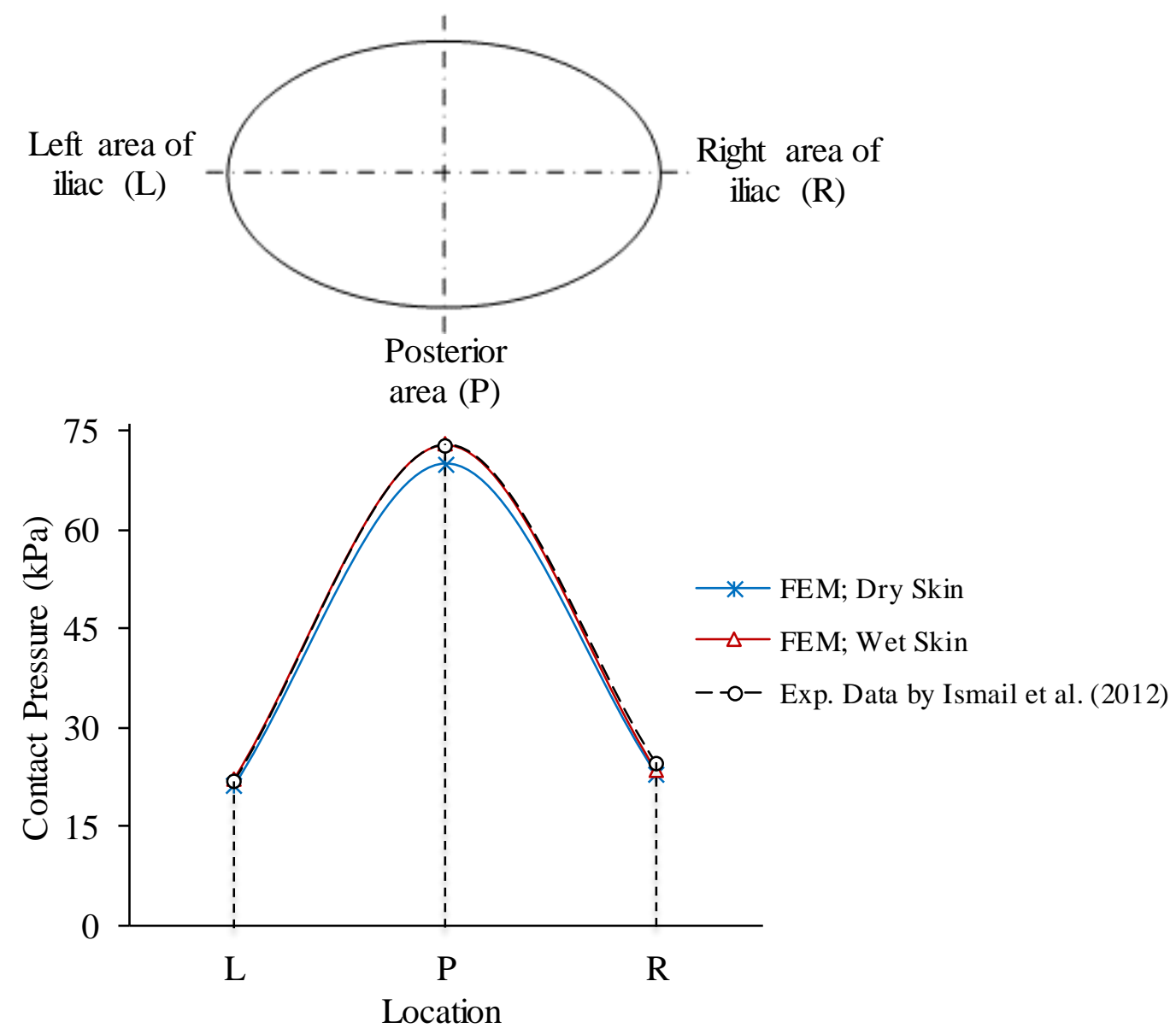

Figure 11. The maximum contact pressure on the posterior, left area of the iliac and right area of the iliac.

The compression force of the pelvic binder used in this study was $180 \mathrm{~N}$. Determination of compression force was estimated on a pelvic binder in order to reduce contact pressure on the unstable pelvic fracture. Figure 12 shows the contact pressure exerted in the left and right area of the iliac for wet and dry skin conditions. It can be seen that the contact pressure on the tissue interface was found to increase with increasing loading rate. The maximum pressure on the left area of the iliac was 21.16 $\mathrm{kPa}$ for dry skin and $22.31 \mathrm{kPa}$ for wet skin, while the maximum contact pressure on the right area of the iliac was $22.97 \mathrm{kPa}$ for dry skin and $23.56 \mathrm{kPa}$ for wet skin. From Figure 12, the maximum load during the tightening process should be kept below $60 \mathrm{~N}$ for dry skin and $40 \mathrm{~N}$ for wet skin thus, reducing the possibility of pelvic injury [5]. This is also to prevent pressure sores on the left and right area of the iliac. Figure 13 however, exhibits different values between the anterior and posterior compared to to the left and right area of the iliac. The anterior area gives a maximum value of $120 \mathrm{~N}$ for both wet and dry conditions, while the posterior shows a significantly lower value with $20 \mathrm{~N}$ for both conditions. The reason is because the patient was lying down on the spine board. 


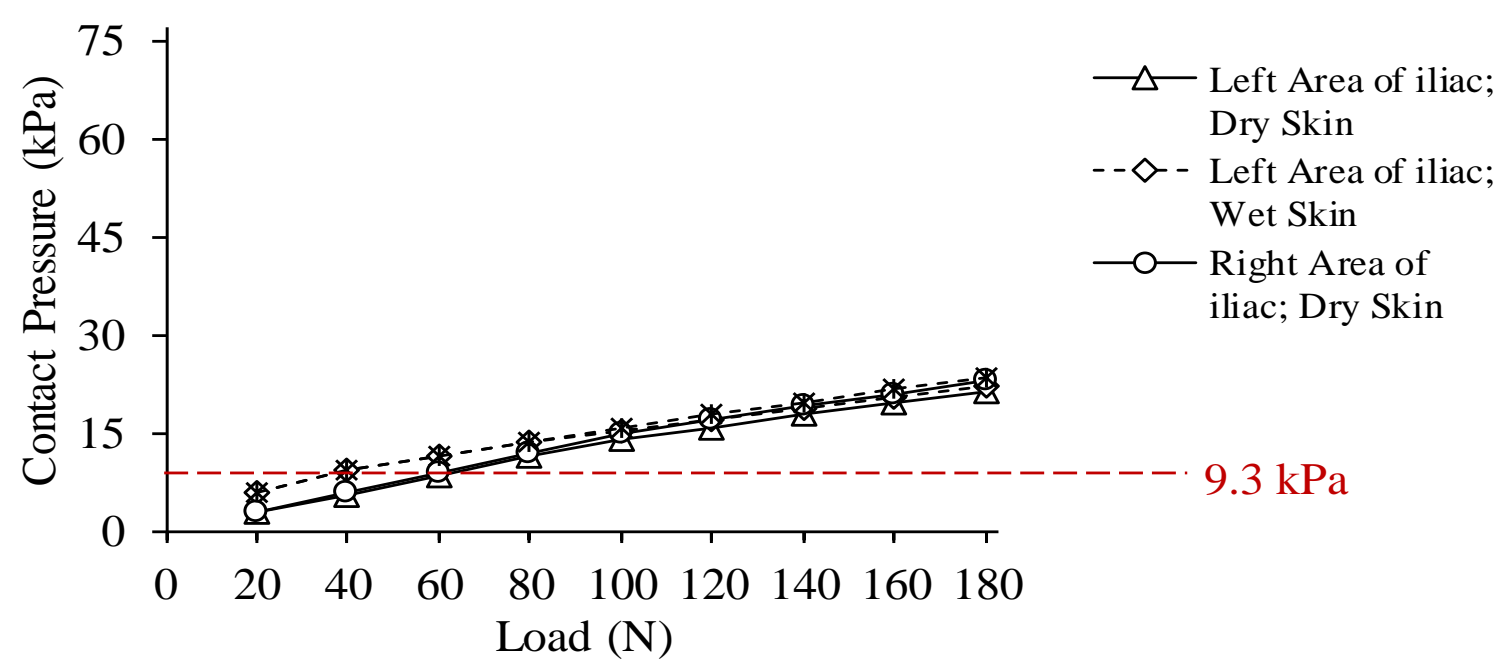

Figure 12. The contact pressure exerted on the left and right area of the iliac for wet and dry skin.

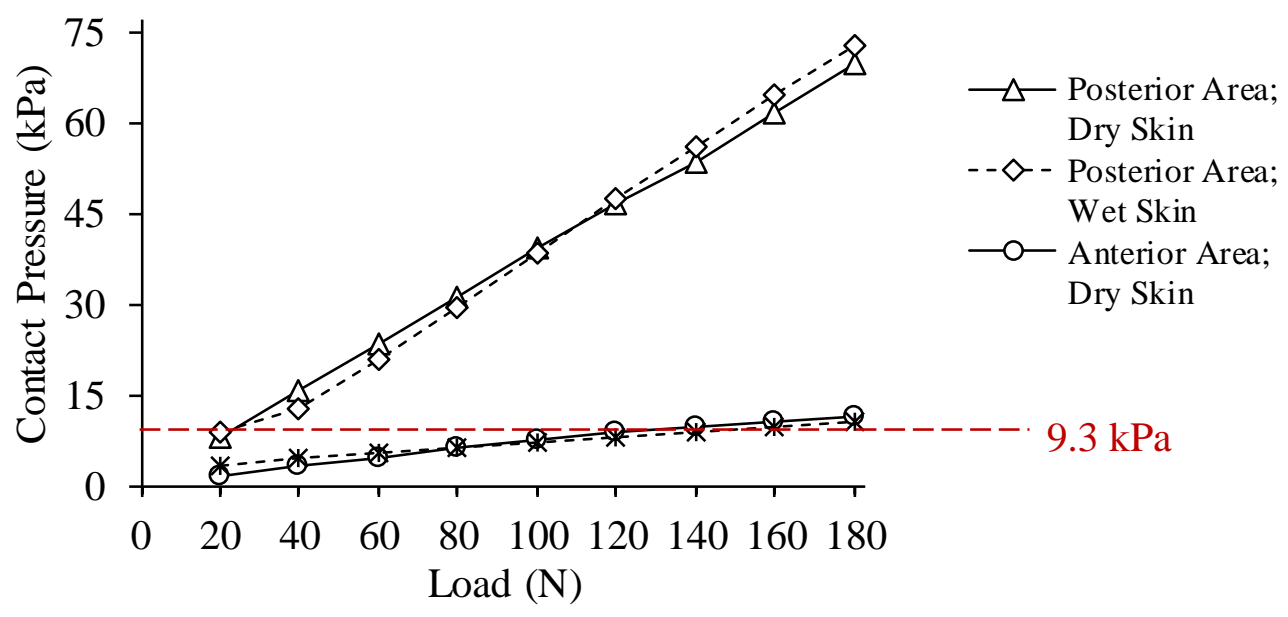

Figure 13. The contact pressure exerted on the posterior and anterior area for wet and dry skin.

In addition, the weight of the patient also needs to be included thus the load is minimal compared with other areas. If the load is greater than $20 \mathrm{~N}$, the pressure will increase proportionally resulting in pressure sores. Contact pressure was exerted on the posterior and anterior area for wet and dry skin conditions. The maximum contact pressure exerted by the pelvic binder on human tissue occurred in the posterior area, while the minimum contact pressure occurred on the anterior area. The maximum pressure on the posterior area was $69.94 \mathrm{kPa}$ for dry skin and $73.05 \mathrm{kPa}$ for wet skin, while the maximum contact pressure on the anterior area was $11.58 \mathrm{kPa}$ for dry skin and $10.69 \mathrm{kPa}$ for wet skin. The analysis results showed that the contact pressure obtained from the present work exceeded the pressure recommended by the manufacturers i.e. $\geq 9.3 \mathrm{kPa}$. This condition can lead to tissue damage after a prolonged period when pressure on the tissue interfaces is not controlled [4, 6, 8]. Hence, to prevent tissue 
damage there must be a cushion between the pelvic binder and human tissue to reduce the effects of tissue reaction from the prehospital device.

\section{CONCLUSIONS}

The FE model of the tissue-PCCDs contact interface was developed to study the effects of human tissue interactions in the pelvic compression binder. The material parameters for human tissue was modelled and validated from previous researchers. The FE model was developed using ABAQUS following a standard model from CIRS Dynamic Pelvis Phantom. From the FE results, the contact pressure distribution was validated by experiments performed by Knops and Ismail. Their studies were executed based on volunteer experiments. The results showed that the FE model of the tissue-PCCDs contact interfaces was able to predict exerted pressure and location of maximum contact pressure. Irregular and uneven pressure distribution patterns were exhibited during the process of tightening the PCCDs straps. The analysis also provided the effect of friction coefficients on tissue-PCCDs contact interface in wet and dry conditions. It showed minor differences in contact pressure for both wet and dry conditions. The value of contact pressure obtained from all areas of tissue interfaces led to the build-up of pressure sores, which can cause tissue damage after a prolonged period of time. Hence, a cushion should be introduced to avoid tissue damage while reducing the patient effect due to the prehospital equipment. This study was limited to static conditions represented by the patient on a spine board. However, it provides significant findings on the interactions between human tissue and pelvic binder during tightening of the PCCDs straps. Hence, further studies could be conducted especially for dynamic cases and cushions could be introduced to PCCDs to reduce contact pressure and subsequently, pressure sores.

\section{ACKNOWLEDGEMENTS}

The authors would like to express their gratitude to research grant from Universiti Kebangsaan Malaysia (PRGS/1/11/TK/UKM/02/2) and research team from UKM for undivided support this research.

\section{REFERENCES}

[1] Krieg JC, Mohr M, Ellis TJ, Simpson TS, Madey SM, Bottlang M. Emergent stabilization of pelvic ring injuries by controlled circumferential compression: a clinical trial. Journal of Trauma and Acute Care Surgery. 2005;59:659-64.

[2] DeAngelis NA, Wixted JJ, Drew J, Eskander MS, Eskander JP, French BG. Use of the trauma pelvic orthotic device (T-POD) for provisional stabilisation of anterior-posterior compression type pelvic fractures: a cadaveric study. Injury. 2008;39:903-6.

[3] Ismail M, Johar M, Krishnian B, Mohd Radhi A, Saadah N, Gan K. Development of the pelvic and lower limb immobilization device: a Universiti Kebangsaan Malaysia (UKM) innovation project. Medicine \& Health. 2012;7:111.

[4] Prasarn ML, Horodyski M, Schneider PS, Pernik MN, Gary JL, Rechtine GR. Comparison of skin pressure measurements with the use of pelvic 
circumferential compression devices on pelvic ring injuries. Injury. 2016;47:717-20.

[5] Hedrick-Thompson J. A review of pressure reduction device studies. Journal of vascular nursing: official publication of the Society for Peripheral Vascular Nursing. 1992;10:3-5.

[6] Jowett A, Bowyer G. Pressure characteristics of pelvic binders. Injury. 2007;38:118-21.

[7] Lieshout E, Goossens R, Riel M, Patka P, Knops S, Schipper I. Measurements of the Exerted Pressure by Pelvic Circumferential Compression Devices. Surgery and Traumatology. 2010.

[8] Knops SP, Van Lieshout EM, Spanjersberg WR, Patka P, Schipper IB. Randomised clinical trial comparing pressure characteristics of pelvic circumferential compression devices in healthy volunteers. Injury. 2011;42:1020-6.

[9] Tang CY, Chan W, Tsui CP. Finite element analysis of contact pressures between seat cushion and human buttock-thigh tissue. Engineering. 2010;2:720.

[10] Tak-Man CJ, Ming Z. Parametric design of pressure-relieving foot orthosis using statistics-based finite element method. Medical Engineering \& Physics. 2008;30:269-77.

[11] Grujicic M, Pandurangan B, Arakere G, Bell W, He T, Xie X. Seat-cushion and soft-tissue material modeling and a finite element investigation of the seating comfort for passenger-vehicle occupants. Materials \& Design. 2009;30:4273-85.

[12] Levy A, Kopplin K, Gefen A. Simulations of skin and subcutaneous tissue loading in the buttocks while regaining weight-bearing after a push-up in wheelchair users. Journal of the Mechanical Behavior of Biomedical Materials. 2013;28:436-47.

[13] Levy A, Kopplin K, Gefen A. An air-cell-based cushion for pressure ulcer protection remarkably reduces tissue stresses in the seated buttocks with respect to foams: finite element studies. Journal of Tissue Viability. 2014;23:13-23.

[14] Mohanty PP, Mahapatra S. A finite element approach for analyzing the effect of cushion type and thickness on pressure ulcer. International Journal of Industrial Ergonomics. 2014;44:499-509.

[15] Wu JZ, Wimer BM, Welcome DE, Dong RG. An analysis of contact stiffness between a finger and an object when wearing an air-cushioned glove: The effects of the air pressure. Medical Engineering \& Physics. 2012;34:386-93.

[16] Verver M, Van Hoof J, Oomens C, Wismans J, Baaijens F. A finite element model of the human buttocks for prediction of seat pressure distributions. Computer Methods in Biomechanics and Biomedical Engineering. 2004;7:193203.

[17] Rashid B, Destrade M, Gilchrist MD. Determination of friction coefficient in unconfined compression of brain tissue. Journal of the Mechanical Behavior of Biomedical Materials. 2012;14:163-71.

[18] Wu JZ, Dong RG, Schopper AW. Analysis of effects of friction on the deformation behavior of soft tissues in unconfined compression tests. Journal of Biomechanics. 2004;37:147-55.

[19] Rotaru G-M, Pille D, Lehmeier F, Stämpfli R, Scheel-Sailer A, Rossi R, et al. Friction between human skin and medical textiles for decubitus prevention. Tribology International. 2013;65:91-6. 
[20] Kahle W, Leonhardt H, Platzer W, Palmer E, Platzer W. Color atlas and textbook of human anatomy. Vol. 1, Locomotor system: Thieme; 2004.

[21] Snell RS. Clinical anatomy by regions: Lippincott Williams \& Wilkins; 2011.

[22] Tan LB, Tse KM, Lee HP, Tan VBC, Lim SP. Performance of an advanced combat helmet with different interior cushioning systems in ballistic impact: Experiments and finite element simulations. International Journal of Impact Engineering. 2012;50:99-112.

[23] Annaidh AN, Bruyere K, Destrade M, Gilchrist MD, Maurini C, Otténio M, et al. Automated estimation of collagen fibre dispersion in the dermis and its contribution to the anisotropic behaviour of skin. Annals of Biomedical Engineering. 2012;40:1666-78.

[24] Annaidh AN, Bruyère K, Destrade M, Gilchrist MD, Otténio $M$. Characterization of the anisotropic mechanical properties of excised human skin. Journal of the Mechanical Behavior of Biomedical Materials. 2012;5:139-48.

[25] Flynn C, Taberner AJ, Nielsen PM, Fels S. Simulating the three-dimensional deformation of in vivo facial skin. Journal of the Mechanical Behavior of Biomedical Materials. 2013;28:484-94.

[26] Flynn C, Taberner A, Nielsen P. Measurement of the force-displacement response of in vivo human skin under a rich set of deformations. Medical Engineering \& Physics. 2011;33:610-9.

[27] Grap MJ, Munro CL, Wetzel PA, Schubert CM, Pepperl A, Burk RS, et al. Tissue interface pressure and skin integrity in critically ill, mechanically ventilated patients. Intensive and Critical Care Nursing. 2017;38:1-9. 